\title{
Using simulation to implement a general anaesthesia checklist for caesarean sections
}

\author{
A. Doolan', L. Dockrell', C. Murphy ${ }^{1}$ \\ 1Our Lady Of Lourdes Hospital, Drogheda, - Co.Louth (Ireland)
}

\section{Background:}

Following an audit of obstetric general anaesthesia (GA) practice, difficult obstetric intubation rates (14.6\%) in our institution were found to be higher than reported $(0.64 \%$ to $5.7 \%)^{1,2}$. Improper airway assessment and planning can contribute significantly to adverse airway events ${ }^{3,4}$. The use of a GA checklist may facilitate preparation ${ }^{5}$.

\section{Materials and Methods:}

A retrospective chart review auditing obstetric GA practice over 6 months was performed. A checklist was developed (figure 1). Anaesthetic trainees participated in a simulation of an obese parturient for Category 1 GA caesarean delivery (CD) without, and subsequently with the checklist. The checklist was modified, introduced into clinical practice and reviewed 1 year later.

\section{Results and Discussion:}

In $2015,7.5 \%$ of CDs were performed under GA. The GA audit revealed $45 \%(18 / 41)$ of GA CDs occurred after-hours. $46 \%$ (19/41) were category 1 .
The difficult intubation rate was 15\% (6/41). Five patients had a Cormack-Lehane grade 3 and one patient had elective awake fibre-optic intubation

Simulation identified the omission of essential steps in airway preparation. Only $55 \%$ of trainee (11/20) ensured suction functioned, $50 \%$ (10/20) confirmed bougie at-hand and $20 \%$ (4/20) checked they had a 2nd generation LMA available. $45 \%$ (9/20) put the patient head up and 20\% (4/20) pre-oxygenated to ET 02 of $>0.9$. Repeated simulation with use of a checklist during pre-oxygenation did not delay time to induction.

Despite $95 \%$ of trainees stating it improved safety, only $57 \%$ of trainees and $54 \%$ of nurses had incorporated it into routine practice 1 year later.

\section{Conclusion:}

There is a high rate of difficult intubation in our unit and a significant proportion of GA CDs happen out-of-hours. Whilst introduction of a checklist improved preparation, poor compliance remains a challenge despite education and training.

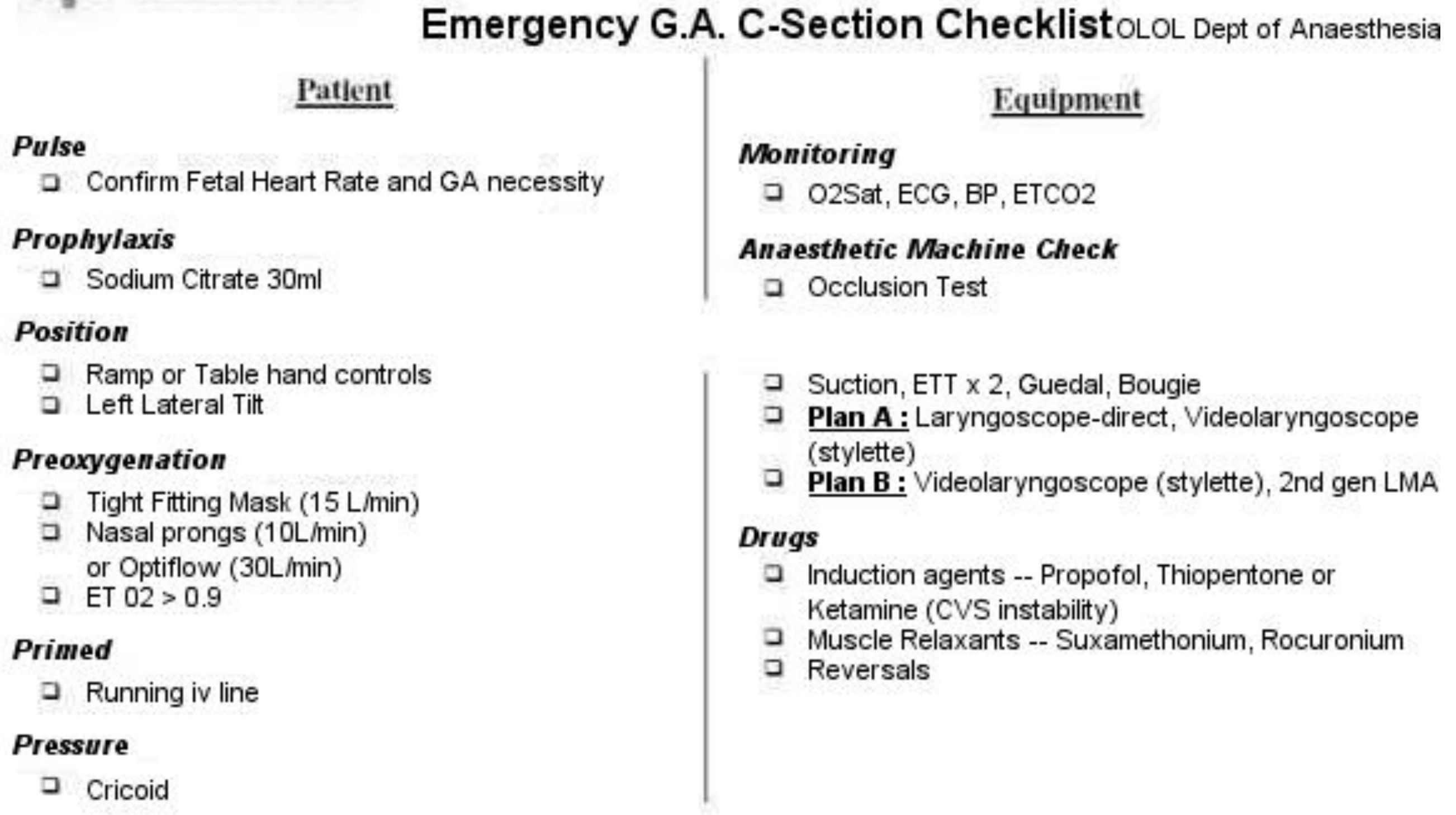

References:

1. Djabatey, E. A. and Barclay, P. M. Anaesthesia 2009;64:1168-1171

2. McKeen DM., et al. CJA 2011;58(6):514-24

3. Cook TM, et al. BJA 2011;106(5):632-42

4. Mushambi MC, et al. Anaesthesia 2015;70(11):1286-1306

5. James B, et al. Anaesthesia 2015;24: S24 6. Joy S et al.RCOA 2012. pp. 224-5 